\title{
Celecoxib induces anoikis in human colon carcinoma cells associated with the deregulation of focal adhesions and nuclear translocation of p130Cas
}

\author{
Isolda Casanova ${ }^{1}$, Matilde Parreño ${ }^{1}$, Lourdes Farré ${ }^{1}$, Sílvia Guerrero ${ }^{1}$, M. Virtudes Céspedes ${ }^{1}$, Miguel Angel Pavon ${ }^{1}$, \\ Francesc J. Sancho ${ }^{2}$, Eugenio Marcuello ${ }^{3}$, Manuel Trias ${ }^{4}$ and Ramon Mangues ${ }^{1 *}$ \\ ${ }^{1}$ Laboratori d'Investigació Gastrointestinal de l'Institut de Recerca of the Hospital de la Santa Creu i Sant Pau, Barcelona, Spain \\ ${ }^{2}$ Deparment of Pathology of the Hospital de la Santa Creu i Sant Pau, Barcelona, Spain \\ ${ }^{3}$ Deparment of Medical Oncology of the Hospital de la Santa Creu i Sant Pau, Barcelona, Spain \\ ${ }^{4}$ Deparment of Surgery of the Hospital de la Santa Creu $i$ Sant Pau, Barcelona, Spain
}

\begin{abstract}
Celecoxib, a selective cyclooxygenase-2 (COX-2) inhibitor, is effective as chemopreventive against colon cancer and it is the only nonsteoroidal antiinflammatory drug approved by the FDA for adjuvant therapy in patients with familial adenomatous polyposis. It is also being evaluated, within Phase II and III clinical trials, in combination with standard chemotherapy to treat sporadic colorectal cancer. Nevertheless, its antitumor mechanism of action is still not fully understood. In this study, we have evaluated the in vitro growth inhibitory effect of celecoxib in colon carcinoma cells and analyzed its mechanism of action. We report that the deregulation of the focal adhesion assembly protein Crk-associated substrate $130 \mathrm{kDa}$ (p130Cas) by celecoxib plays a relevant role in the cytotoxic effect of this drug. Thus, celecoxib induces the proteolysis of p130Cas and the nuclear translocation of the $31 \mathrm{kDa}$ generated fragment leading to apoptosis. Furthermore, overexpression of wild-type p130Cas reverts, in part, the growth inhibitory effect of celecoxib. In contrast, FAK and AKT do not appear to be involved in this activity. Our data suggest, for the first time, that the antitumor mechanism of action of celecoxib includes the induction of anoikis, an effect that is not related to COX-2 inhibition. Besides providing new insights into the antitumor effect of celecoxib, this novel mechanism of action holds potential relevance in drug development. Indeed, our results open the possibility to develop new celecoxib derivatives that induce anoikis without COX-2 inhibition so as to avoid the cardiovascular toxicity recently described for the COX-2 inhibitors.

(C) 2005 Wiley-Liss, Inc.
\end{abstract}

Key words: anoikis; celecoxib; p130Cas; focal adhesion kinase (FAK); colorectal cancer

Treatment of patients, with or without a genetic predisposition to colon cancer, with nonsteroidal antiinflammatory drugs

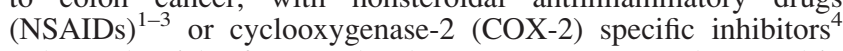
reduces the risk of tumor development. Moreover, when used in chemopreventive protocols, COX-2 inhibitors delay the development of colon adenomas and their transition to carcinomas, 3,5 and are active in treating established tumors as single agents. ${ }^{6,7}$ Celecoxib is a selective COX-2 inhibitor that has demonstrated chemopreventive activity in familial adenomatous polyposis ${ }^{4}$ and has been approved by the Food and Drug Administration (FDA) for its clinical use in cancer. In addition, combinations of celecoxib and standard chemotherapy for sporadic colorectal cancer are being evaluated in randomized trials. ${ }^{8}$ Nevertheless, the mechanism of the antitumor effect of this drug is still unclear and there is an open controversy on its dependency on COX-2 inhibition. Further knowledge on the mechanism of action of celecoxib will increase the probability of having a significant impact on the clinical course of colorectal cancer and on the development of more potent drugs.

The antitumor effect of celecoxib has been described in many different carcinoma cell types. Although many authors suggest that its effect is caused by the induction of apoptosis in colon, ${ }^{9,10}$ prostate, ${ }^{11}$ cholangiocarcinoma ${ }^{12}$ or hepatocellular ${ }^{13}$ carcinoma cells, the precise pathways involved in this induction are starting now to be elucidated. Thus, different pathways have been related to celecoxib apoptotic effect, such as the alteration of PDK/Akt and $\mathrm{Bad},{ }^{14}$ the activation of $\mathrm{NF \kappa B}^{15}$ or the release of mitochondrial cytochrome C. ${ }^{16}$

In this study, we have further explored the mechanism of action of celecoxib, in colon carcinoma cells. On the basis of the previous reports on NSAIDs modulation of integrin mediated signaling pathways, ${ }^{17,18}$ we evaluated whether celecoxib could alter cell signaling from different proteins that regulate focal adhesions.

Focal adhesion complexes are structures that link the actin filaments of the cytoskeleton and the extracellular matrix (ECM). The signaling pathways mediated by these complexes play an important role in the regulation of cell survival and apoptosis. ${ }^{19}$ For this reason, deregulation of focal adhesion complexes and loss of cell attachment to the ECM induce cell death through a specific apoptotic process termed anoikis. ${ }^{20}$ Resistance to anoikis confers a selective advantage upon precancerous epithelial cells and contributes prominently to malignancy in colon cancer. ${ }^{21}$ Thus, agents that induce anoikis could theoretically halt this malignant process. To our knowledge, no previous reports have related celecoxib antitumor effect with deregulation of focal adhesion proteins.

Different proteins that compose focal adhesion complexes have been involved in the regulation of anoikis; among them, focal adhesion kinase (FAK) and Crk-associated substrate $130 \mathrm{kDa}$ (p130Cas) are particularly important. FAK is a cytoplasmic nonreceptor tyrosine kinase, which is activated by autophosphorylation upon integrin-dependent adhesion, ${ }^{22}$ or after growth factor or hormone stimulation. ${ }^{23}$ Tyrosine phosphorylation of FAK plays a central role in signaling from integrins, creating multiple binding sites for different signaling and adapter proteins, such as Src, ${ }^{24}$ PI3K, ${ }^{25} \mathrm{Grb}_{2}{ }^{26} \mathrm{PTEN}^{27}$ and p130Cas. ${ }^{28}$ p130Cas is a docking protein that integrates signals that control cell transformation, cell adhesion, actin organization, and cell migration. ${ }^{29,30}$ It is also involved in the regulation of cell death; its overexpression protects from apoptosis whereas dominant-negative forms of p130Cas induce cell death. ${ }^{31,32}$ Proteolysis of p130Cas has been associated with the induction of apoptosis by different agents ${ }^{33,34}$ and generates a fragment of $31 \mathrm{kDa}$ that is translocated to the nucleus where it acts as a transcriptional repressor. ${ }^{35}$

We show here, for the first time, that celecoxib induces anoikis in human colon carcinoma cells. Anoikis induction is associated with proteolysis and translocation of p130Cas to the nucleus in all tested cell lines; however, this effect does not correlate with FAK or AKT dephosphorylation. We also report that, in contrast to the

Grant sponsor: The Spanish Government; Grant numbers: SAF03/ 07437, FIS 01/0853, FISC03/10; Grant sponsor: Spanish National Health System; Grant numbers: FIS 98/3197, FIS 01/3085.

*Correspondence to: Laboratori d'Investigació Gastrointestinal, Institut de Recerca, Hospital de Sant Pau, Av. Sant Antoni M. Claret, 167, 08025 Barcelona, Spain. Fax: 34-93-4552331.

E-mail: rmangues@santpau.es

Received 20 May 2005; Accepted 7 October 2005

DOI 10.1002/ijc. 21662

Published online 13 December 2005 in Wiley InterScience (www. interscience.wiley.com). 
expression of activated FAK, the overexpression of wild-type p130Cas diminishes the antitumor effect of celecoxib.

\section{Material and methods \\ Cell lines and culture conditions}

TD20 and NC59 cell lines were previously established in our laboratory from 2 colon carcinoma patients who did not have any previous history of chemo or radiotherapy treatment. These cell lines were characterized for the most common mutations in colorectal cancer. ${ }^{36}$ Both carry the $K$-ras wild-type gene; TD20 has a mutation in the p53 tumor suppressor gene and NC59 carries a wild-type p53. HCA7 cells were kindly provided by Dr. Susan Kirkland and HT29 cells were obtained from the ATCC. All cell lines were cultured in DMEM (25 mM Hepes), except for HCA7, which was cultured in DMOD medium. In all cases, medium was supplemented with $10 \%$ fetal bovine serum, $1 \%$ glutamine, 100 units/ml penicillin/streptomycin (Life Technologies, Inc.), and cells were incubated at $37^{\circ} \mathrm{C}$ in a humidified atmosphere containing $5 \% \mathrm{CO}_{2}$.

Celecoxib was synthesized by Laboratories Esteve S.A. and the stock solution reconstituted in DMSO and diluted in culture media before use.

\section{Antitumor activity}

We compared the antitumor effect of celecoxib against the TD20, HCA7, HT29 and NC59 cell lines. Antitumor activity was evaluated measuring cell metabolic capacity (viability), using the Cell Proliferation Kit II (XTT) and following the recommendations of the manufacturer (Roche Diagnostics). The assays were carried out in triplicates, with controls containing unexposed cells, cells with vehicle, or media plus compound. Cells were seeded into 96 -well plates $\left(5 \times 10^{3}\right.$ cells/well $)$ in $100 \mu \mathrm{l}$ of media and incubated for $24 \mathrm{hr}$. Afterwards, celecoxib at 1, 20, 40,60 and $80 \mu \mathrm{M}$ concentrations or vehicle were added, and incubated for $60 \mathrm{hr}$. At the end of the incubation period, we added $50 \mu \mathrm{l}$ of a mixture containing XTT and electron coupling reagent to each well. After $4 \mathrm{hr}$ of incubation at $37^{\circ} \mathrm{C}$, we read the absorbance at $490 \mathrm{~nm}$. The growth inhibitory activity was obtained by subtracting the absorbance of the blanks and expressed as percentage of cell growth inhibition, as compared with untreated controls.

\section{Apoptotic induction}

To evaluate the apoptotic capacity of celecoxib, we performed nuclear staining with the Hoescht 3342 dye (Sigma) in cells exposed to compound or vehicle (DMSO) for $24 \mathrm{hr}$. Once the incubation was finished, the media was collected and centrifuged to obtain the suspended cells. We rinsed with PBS, at $\mathrm{pH} 7.4$ $\left(\mathrm{Ca}^{2+}\right.$ and $\mathrm{Mg}^{2+}$ free), and centrifuged again to collect the cells that could remain in suspension. The adhered cells were trypsinized and pulled together with those previously obtained. These cells were fixed (3.7\% p-formaldehyde in PBS, pH 7.4) for $10 \mathrm{~min}$ at $-20^{\circ} \mathrm{C}$ and rinsed 3 times with PBS. They were, afterwards, permeabilized $(0.5 \%$ Triton X-100 in PBS $\mathrm{pH} 7.4)$ for 5 min at RT and rinsed twice with PBS. Following, cells were stained with Hoescht dye (50 $\mathrm{ng} / \mathrm{ml}$ in PBS $\mathrm{pH}$ 7.4) for 10-30 min at RT, in the dark. Then, cells were rinsed with distilled water and resuspended in $10 \mu \mathrm{l}$ of PBS. Finally, we mounted the cells on a slide, leaving the sample to dry and observing the appearance of the nuclei under a fluorescence microscope, to count the total and the apoptotic cell number. Cells that showed nuclear condensation and/or fragmentation were identified as apoptotic.

We also tried to assess if the cells that were detached by the effect of celecoxib remained or not viable, in order to know if detachment occurred before apoptosis. To that purpose, we stained floating cells with trypan blue during $5 \mathrm{~min}$ and counted the number of viable (nonstained) and nonviable (blue stained) cells.

\section{Signal transduction analysis by Western blot}

We analyzed the alteration of the signal transduction pathways associated with the regulation of apoptosis and the focal adhesion proteins in protein extracts of TD20, NC59, HT29 and HCA7 cells exposed to $60 \mu \mathrm{M}$ celecoxib for different periods of time. After exposure to the compound, whole cell lysates were prepared and Western blot performed as previously described. ${ }^{37}$ Dilutions in TBS-T, containing $0.1 \%$ BSA or $1 \%$ nonfat dried milk, for primary antibodies were as follows: rabbit anti-COX-2 (Cayman Chemical, 1:8,000), rabbit anti-COX-1 (Cayman Chemical, 1:1,000), mouse anti-p130Cas (BD, Pharmingen, 1:4,000), rabbit anti-p130Cas Tyr410 (Cell Signalling, 1:1,000), mouse anti-FAK (BD, Pharmingen, 1:4,000), mouse anti-FAK Tyr397 (BD, Pharmingen, 1:4,000), mouse anti-AKT (BD, Pharmingen, 1:2,000), rabbit anti-AKT Thr308 (Cell Signalling, 1:1,000), rabbit anti-Caspase 9 (Cell Signalling, 1:5,000), rabbit anti-Caspase8 (BD Pharmingen, 1:5,000), mouse anti-cytochrome c (BD Pharmingen, 1:1,000), goat anti-actin (Santa Cruz Biotechnologies, 1:20,000) or mouse anti-c-Myc (BD Pharmingen, 1:1,000).

\section{Protein extraction of the cytosolic fraction}

To determine the release of cytochrome $\mathrm{C}$ from mitochondria, we measured its level in the cytosol in control cells and after treatment with $60 \mu \mathrm{M}$ Celecoxib for $15 \mathrm{hr}$. We seeded TD20 or HCA7 cells in $100 \mathrm{~mm}$ plates and treated them with the compound or vehicle. Then, we collected the supernatant and trypsinized the adhered cells pulling them together. Following, we centrifuged the cells for $10 \mathrm{~min}$ at $400 \mathrm{~g}$, washed the pellet with extraction buffer (20 mM Hepes pH 7.5, $10 \mathrm{mM} \mathrm{KCl}, 1.5 \mathrm{mM} \mathrm{MgCl}_{2}, 1 \mathrm{mM}$ EDTA, $1 \mathrm{mM}$ EGTA, $250 \mathrm{mM}$ Sucrose, $1 \mathrm{mM}$ DTT, $0.1 \mathrm{mM}$ PMSF, $5 \mu \mathrm{g} / \mathrm{ml}$ pepstatin A, $10 \mu \mathrm{g} / \mathrm{ml}$ leupeptin, $2 \mu \mathrm{g} / \mathrm{ml}$ aprotinin) and centrifuged again. Afterwards, cells were resuspended with extraction buffer and incubated on ice for $30 \mathrm{~min}$. Finally, cells were homogenized with a glass piston (pestle B) for 15 times and centrifuged twice at $20,000 \mathrm{~g}$ for $30 \mathrm{~min}$. Supernatants were kept at $-80^{\circ} \mathrm{C}$ until immunoblotting of cytochrome $\mathrm{C}$ was performed, with the corresponding antibody, as described above.

\section{Immunofluorescence analysis of p130Cas}

Cells were seeded into 8-well chamber slides and treated with $60 \mu \mathrm{M}$ Celecoxib or vehicle for $15 \mathrm{hr}$. Immunofluorescence analysis of p130Cas was performed in adhered cells and in supernatants after collecting by centrifugation with a citospin. Cells were rinsed 3 times in PBS and fixed with cold methanol for $1 \mathrm{~min}$ at $-20^{\circ} \mathrm{C}$. Then, cells were washed again 3 times with PBS and blocked for $1 \mathrm{hr}$ in $1 \%$ BSA on PBS at RT. Afterwards, cells were washed with PBS and incubated with p130Cas antibody (BD Pharmingen, 1:100) for $1 \mathrm{hr}$. Then, cells were washed with PBS and incubated with the secondary antibody (anti-mouse TRITC, 1:100) and Hoescht dye $(50 \mathrm{ng} / \mathrm{ml})$. Finally, cells were washed with PBS and cover slips were mounted using Fluoprep (Biomérieux).

\section{Plasmid constructs and transfection}

Plasmid constructs containing full-length CAS (CAS-FL, amino acids 1-874) or active FAK (Myr-FAK) were used to transiently transfect TD20 cells. CAS-FL plasmid was a generous gift from Dr. Amy $\mathrm{H}$. Bouton and is described in Burnham et al. ${ }^{38} \mathrm{Myr}-$ FAK plasmid was gently provided by Dr. Silvio Gutkind and is described in Igishi et al. ${ }^{39}$ The day before transfection, we seeded $4 \times 10^{6}$ TD20 cells in $100 \mathrm{~mm}$ plates with complete growth medium. The following day, we mixed $20 \mu \mathrm{l}$ of Plus Reagent (Invitrogen) and $15 \mu \mathrm{l}$ of plasmid DNA (pcDNA3, CAS-FL or Myr-FAK) into $750 \mu \mathrm{l}$ medium without serum and incubated for $15 \mathrm{~min}$ at RT. Meanwhile, we diluted $30 \mu \mathrm{l}$ Lipofectamine (Invitrogen) into $50 \mu \mathrm{l}$ medium without serum. Then, we combined diluted DNA and diluted Lipofectamine reagent mixing gently and incubating them for $15 \mathrm{~min}$ at RT. After that, we replaced the medium of the cells with $5 \mathrm{ml}$ of medium without serum and antibiotics. Finally, we overlaid the diluted complex solution onto the 
cells and incubated them for $3 \mathrm{hr}$ at $37^{\circ} \mathrm{C}$, adding afterwards $5 \mathrm{ml}$ of medium containing FBS. The following day, we seeded the transfected cells to perform the protein extracts and the analysis of cell viability by XTT after $4 \mathrm{hr}$ exposure to celecoxib.

\section{Statistical analysis}

The inhibitory concentration $50\left(\mathrm{IC}_{50}\right)$ was determined from the dose-response curves of compound concentration versus percentage of cell viability with the Hill sigmoidal equation (3 parameters), using Sigmaplot 5.0 software. Values of $\mathrm{IC}_{50}$ were compared by the U-Mann Whitney test and statistically significant differences were considered at $p<0.05$.

\section{Results}

\section{Celecoxib inhibits the viability of colon carcinoma cell lines} expressing different levels of $\mathrm{COX}-2$

Because of the previous reports associating inhibition of $\mathrm{COX}-2$ expression with the antitumor activity of celecoxib, ${ }^{40,41}$ we analyzed the effect of this drug on cell viability, using 4 human colon carcinoma cell lines, with different levels of COX-2 expression. As shown in Figure 1a, celecoxib inhibited the viability (reduction of metabolically active cells, as measured by the XTT test) of all 4 cell lines, in a concentration-dependent manner, after $60 \mathrm{hr}$ exposure. To evaluate the differences in the sensitivity of the cell lines to celecoxib, we determined and compared the $\mathrm{IC}_{50}$ values of the 4 cell lines. The $\mathrm{IC}_{50}$ of celecoxib in $\mathrm{TD} 20$ cells was $23.73 \mu \mathrm{M} \pm$ $2.23 \mu \mathrm{M}$, in HCA7 was $33.78 \mu \mathrm{M} \pm 2.42 \mu \mathrm{M}$, in HT29 was $21.66 \mu \mathrm{M} \pm 1.59 \mu \mathrm{M}$ and in NC59 cells was $27.15 \mu \mathrm{M} \pm$

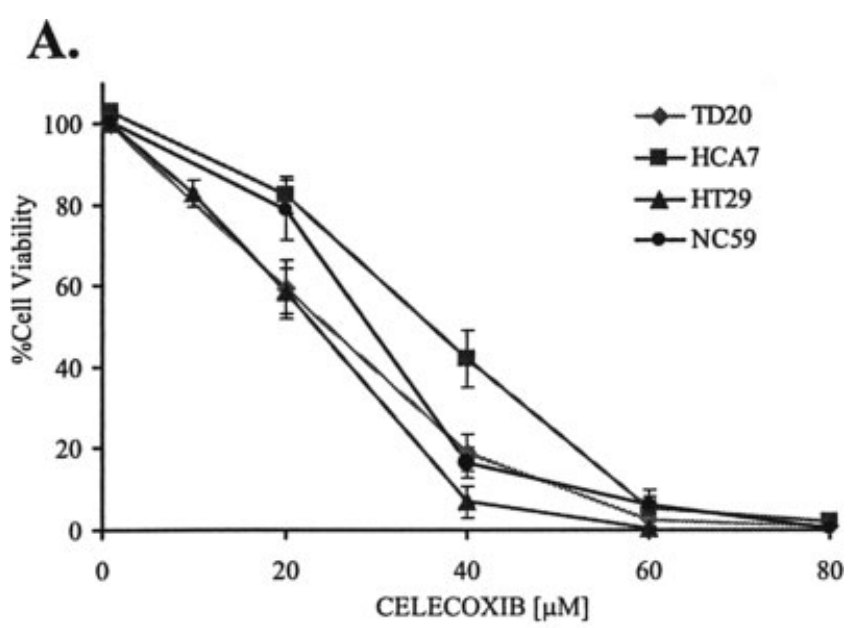

B.

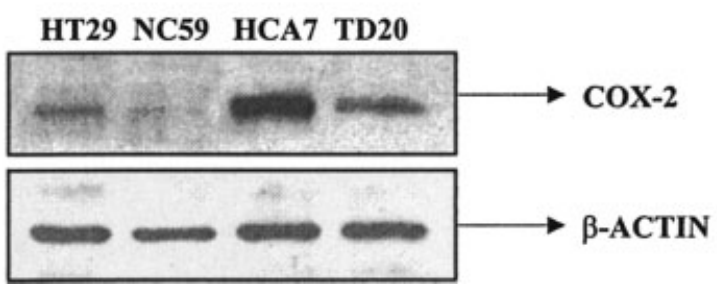

Figure 1 - Celecoxib inhibits the cell viability of all tested human colorectal carcinoma cell lines independently of their level of COX-2 expression. Viability was evaluated by the XTT metabolic assay after $60 \mathrm{hr}$ of drug exposure. (a) Viability/concentration curves for celecoxib on the colorectal carcinoma cell lines TD20, HCA7, HT29 and NC59. All cell lines were similarly sensitive to the growth inhibitory effect of celecoxib in vitro. (b) Expression of COX-2 of the 4 cell lines, as measured by Western blot. Equal protein loading was ensured by immunoblotting against $\beta$-actin.
$1.96 \mu \mathrm{M}$. Interestingly, celecoxib had a similar effect in all cell lines despite their levels of COX-2 expression were significantly different. Thus, despite HCA7 cells showed the highest level of COX-2 expression and NC59 had no detectable expression of the enzyme (Fig. $1 b$ ) their $\mathrm{IC}_{50}$ values were not statistically different (U-Mann Whitney test, $p>0.05$ ). Therefore, we observed a lack of correlation between cell growth inhibition ( $\mathrm{IC}_{50}$ values) and $\mathrm{COX}-2$ levels in the 4 tested cell lines. All 4 cell lines had undetectable levels of COX-1 (data not shown).

\section{Celecoxib induces apoptosis through the activation of the mitochondrial pathway}

To explain the growth inhibitory effect of celecoxib on the colorectal carcinoma cell lines, we explored its capacity to induce apoptosis and its associated morphological and molecular changes. We first tested the induction of apoptosis by Hoescht nuclear staining. After $24 \mathrm{hr}$ of $60 \mu \mathrm{M}$ celecoxib treatment, we observed an increase of apoptotic cells in all tested cell lines, as identified by the presence of nuclear condensation and fragmentation (Fig. 2, panels $b, d, f$ and $h$ ). As expected, the percentage of apoptosis in vehicle-treated cells was negligible $(<1 \%)$ (Fig. 2, panels $a, c, e$ and $g$ ). In agreement with the results obtained in the cell viability assays, there was no correlation between the level of COX-2 and apoptotic induction. Thus, HCA7 and NC59 cells show a similar percentage of apoptotic cells while their COX-2 expression differs substantially (Fig. 1b).
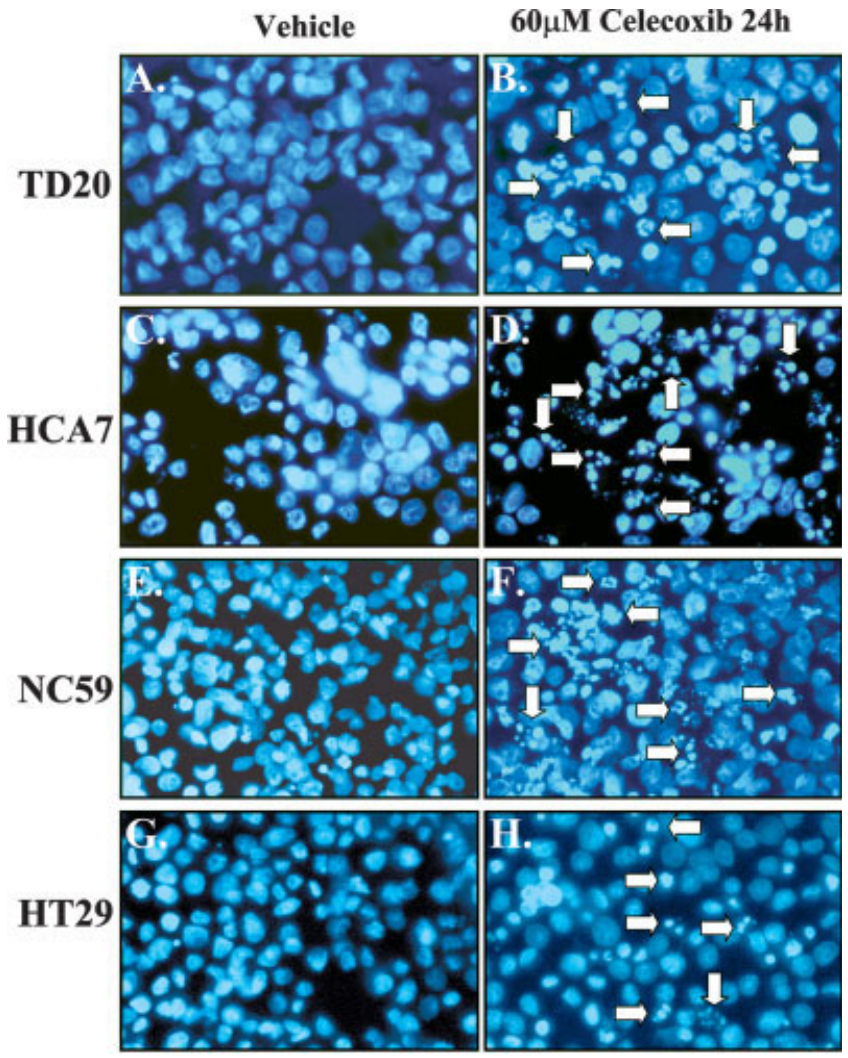

Figure 2 - Celecoxib induces apoptosis in colorectal carcinoma cells after $24 \mathrm{hr}$ exposure. TD20, HCA7, NC59 and HT29 cells were exposed to vehicle $(a, c, e$ and $g$ ) or $60 \mu \mathrm{M}$ celecoxib $(b, d, f$ and $h)$ for $24 \mathrm{hr}$, and apoptotic cells were identified after Hoescht staining. Cells exposed to vehicle ( $a, c, e$ and $g$ ) showed less than $1 \%$ of apoptosis, whereas exposure to celecoxib induced a high number of apoptotic cells, depicting chromatin condensation and nuclear fragmentation (white arrows) ( $b, d, f$ and $h)$. Images were obtained by fluorescence microscopy $(\times 400)$. 
To further explore the mechanism of celecoxib-induced apoptosis, we examined the activation of caspases, key executioners of this process. We analyzed the activation of the initiator caspases 9 and 8 (Fig. 3a). After exposure of TD20, HCA7, NC59 and HT29 cells to $60 \mu \mathrm{M}$ celecoxib at $4,8,15$ or $24 \mathrm{hr}$, we detected the activation of procaspase- 9 , ranging from 4 to $24 \mathrm{hr}$. In contrast, procaspase 8 was not activated at any of these time points (Fig. 3a).

The activation of the initiator caspase 9 by the mitochondrial pathway is caused by the depolarization of the mitochondrial membrane and the release of cytochrome $\mathrm{C}$ to the cytosol. ${ }^{42} \mathrm{On}$ this basis, we wanted to evaluate if the induction of apoptosis by celecoxib was caused by activation of the mitochondrial pathway. For that purpose, we determined the release of cytochrome C, after 15 and $24 \mathrm{hr}$ of exposure to celecoxib, in TD20 or HCA7 cells. In both cell lines, we observed an increase of cytochrome $\mathrm{C}$ in the cytosol at $15 \mathrm{hr}$ of exposure to celecoxib (Fig. $3 b$ ).

Consequently, and confirming previous reports, ${ }^{16,43,44}$ in our system, the induction of apoptosis by celecoxib is caused by the activation of the mitochondrial pathway, including cytochrome $\mathrm{C}$ release to the cytosol and activation of the initiator caspase-9, leading to apoptotic cell death.

\section{Celecoxib induces deregulation of focal adhesion proteins}

Because of our observation that cells exposed to celecoxib become rounded and detached, shortly after exposure to the drug,

A.
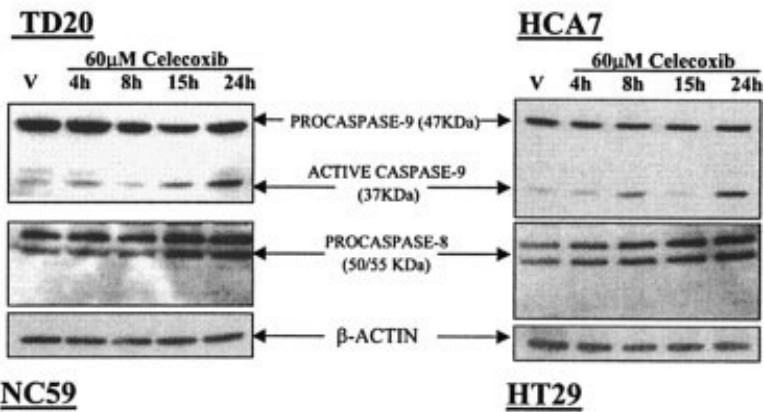

$\underline{\mathrm{NC59}}$

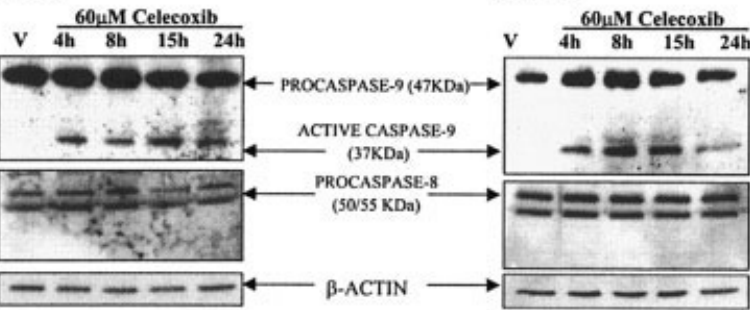

B.

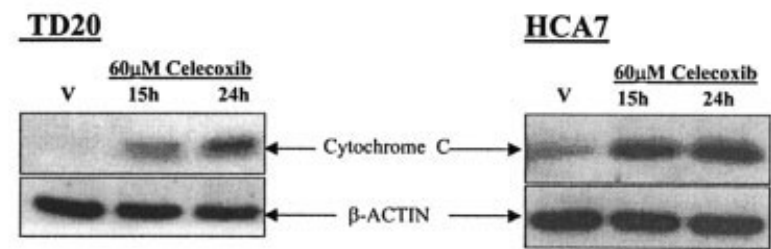

Figure 3 - Signal transduction associated with apoptotic induction after celecoxib treatment of colon carcinoma cells. (a) Expression and activation of procaspases 9 and 8 in TD20, HCA7, NC59 and HT29 cells treated with vehicle (V) or $60 \mu \mathrm{M}$ celecoxib at different time periods $(4,8,15$ and $24 \mathrm{hr})$. In all cell lines, celecoxib activated procaspase 9 but did not induce the cleavage of procaspase-8. Equal loading was checked by immunoblotting against $\beta$-actin. $(b)$ Levels of cytosolic cytochrome C, in TD20 and HCA7 cells, treated with vehicle (V) or $60 \mu \mathrm{M}$ celecoxib for 15 or $24 \mathrm{hr}$. In both cell lines, celecoxib induced the release of cytochrome $\mathrm{C}$ from the mitochondria, as measured by its increase in the cytosol. we tried to assess if the loss of cell attachment occurred before apoptosis. This is because there is a form of apoptosis, termed anoikis, which is induced by loss of cell anchorage and activates the mitochondrial pathway. To that purpose, we stained floating cells with trypan blue to test if they remained viable. We observed a significant number of viable cells, coexisting with nonviable cells (data not shown), but we were unable to accurately quantify their relative percentages.

Therefore, to further evaluate whether or not celecoxib induced anoikis, we assessed the regulation of 3 proteins implicated in focal adhesion signaling (Fig. 4). We determined p130Cas expression and its cleavage to a $31 \mathrm{kDa}$ fragment, after $4,8,15$ and $24 \mathrm{hr}$ of exposure to celecoxib (Fig. 4), since it is a component of the focal adhesion complexes and participates in executing anoikis after detachment from the ECM. ${ }^{45}$ In addition, we determined the expression of FAK and its phosphorylation in Tyr397 as an indicator of FAK activity, and the expression and phosphorylation on Thr308 of AKT, at the same exposure times. In TD20 cells, after $4 \mathrm{hr}$ of exposure to $60 \mu \mathrm{M}$ Celecoxib, p130Cas was downregulated and cleaved, generating the $31 \mathrm{kDa}$ fragment. Although there was not a significant reduction in FAK expression, its activation, as measured by tyrosine phosphorylation, significantly diminished after 8-hr treatment (Fig. 4). We obtained similar results in HCA7 cells; however, proteolysis of p130Cas happened at longer times, and dephosphorylation of FAK was not observed despite its levels of expression diminished at longer times (Fig. 4). Both, HT29 and NC59 cells showed a similar increase in the $31 \mathrm{kDa}$ fragment at $4 \mathrm{hr}$ of celecoxib treatment. In HT29 cells, there was also downre-

\section{TD20}

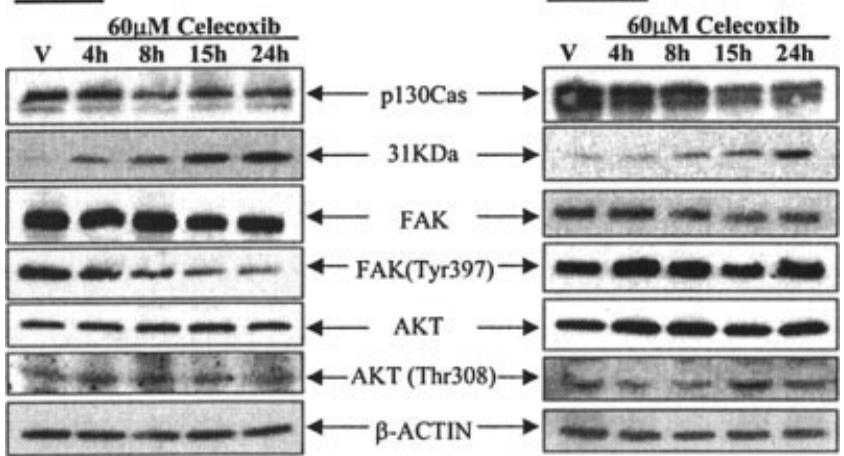

NC59

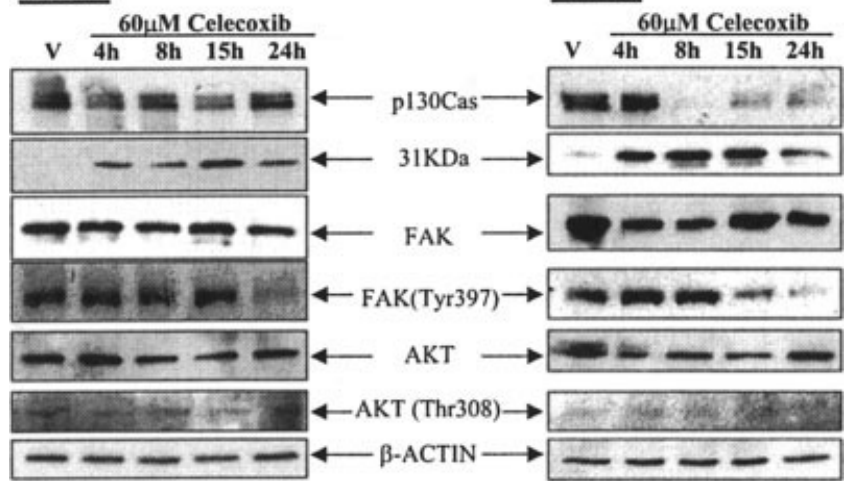

Figure 4 - Regulation of proteins of the focal adhesion contacts, in TD20, HCA7, NC59 and HT29 colorectal carcinoma cells, treated with vehicle (V) or $60 \mu \mathrm{M}$ celecoxib for $4,8,15$ or $24 \mathrm{hr}$. In all cell lines, celecoxib induced the proteolysis of p130Cas, generating a $31 \mathrm{kDa}$ fragment. The effect of celecoxib on FAK expression and activation depends on the tested cell line. AKT expression and phosphorylation remained unchanged in all the analyzed cell lines. Equal loading was ensured by immunoblotting against $\beta$-actin. 
gulation of p130Cas expression and dephosphorylation of FAK at $15 \mathrm{hr}$ of exposure. In NC59 cells, FAK activity did not decrease until $24 \mathrm{hr}$ of celecoxib treatment. Finally, none of the tested cell lines showed alteration of the levels of expression or activation (by Thr308 phosphorylation) of AKT after celecoxib exposure. Thus, we have observed lack of AKT dephosphorylation, and an inconsistent pattern of FAK dephosphorylation, among the tested cell lines, whereas p130Cas proteolysis was a universal finding (Fig. 4).

\section{Celecoxib induces the nuclear translocation of p130Cas}

Based on previous reports describing that the $31 \mathrm{kDa}$ fragment, product of p130Cas cleavage, could be translocated to the nucleus ${ }^{35}$ we determined if celecoxib could also alter the subcellular distribution of p130Cas or of its $31 \mathrm{kDa}$ proteolytic fragment. For that purpose, TD20 and HCA7 cells were exposed to $60 \mu \mathrm{M}$ celecoxib for $15 \mathrm{hr}$ and then stained with an anti-p130Cas mAb, which recognizes both the full length and the $31 \mathrm{kDa}$ fragment of p130Cas. At the same time, we stained the nuclei with Hoescht dye to facilitate the observation of the subcellular localization of p130Cas. In control cells, p130Cas was mainly located in the cytosol and plasma membrane (Fig. $5 a$ ). The combination of both, the anti-p130Cas and the nuclear stain, clearly showed that p130Cas did not localize to the nucleus, as nuclei remained green colored (Fig. 5c). When cells were treated with celecoxib, we observed nuclear staining of p130Cas even though some cytosolic p130Cas was still present (Fig. 5a). This instance, colocalization of p130Cas (red) and Hoescht (green) stain could be distinguished because the nuclei turned yellow when the stains were merged (Fig. 5c). Consequently, celecoxib induces the translocation of p130Cas to the nucleus in both cell lines. Since the antibody we used cannot differentiate between full length and fragmented p130Cas, we cannot conclude that it is the $31 \mathrm{kDa}$ fragment, the one translocating to the nucleus. Nevertheless, this is likely to be the case since the cleaved form is the one that has been described to translocate to the nucleus. ${ }^{35}$
Overexpression of p130Cas reduces the sensitivity of colon carcinoma cells to celecoxib, whereas activated FAK does not

To further evaluate the relevance of the focal adhesion proteins p130Cas and FAK in the apoptosis induced by celecoxib, we transfected TD20 cells with a plasmid containing full-length p130Cas (CAS-FL) or constitutively activated FAK (Myr-FAK). We treated transient transfectants, overexpressing p130Cas or active FAK, with celecoxib for $4 \mathrm{hr}$ and compared the inhibition of cell viability with that of cells transfected with an empty vector (pcDNA3) (Fig. 6a). The $\mathrm{IC}_{50}$ for celecoxib, in CAS-FL transfectants, $(55.66 \pm 5.47 \mu \mathrm{M})$ was significantly higher than the $\mathrm{IC}_{50}$ in cells transfected with the empty vector $(33.58 \pm 5.05 \mu \mathrm{M})(p<$ 0.05, U Mann Whitney test). In contrast, Myr-FAK transfectants had sensitivity to celecoxib similar to control cells ( $\mathrm{IC}_{50}$ of $35.85 \pm$ $3.10 \mu \mathrm{M})$. This result indicates that the overexpression of p130Cas, but not the activation of FAK, blocks the apoptotic effect of celecoxib, and supports the argument that the in vitro antitumor effect of celecoxib is, at least in part caused by the proteolysis of p130Cas. To molecularly analyze the transfectants, we made protein extracts of CAS-FL, Myr-FAK and control transfectants, and analyzed the expression and tyrosine phosphorylation of p130Cas and FAK (Fig. 6b). As expected, the CAS-FL transfectants showed high levels of p130Cas expression and activation, and the Myr-FAK transfectants had higher FAK expression and activation. The levels of expression and phosphorylation of FAK were not altered in CAS-FL transfectants, and p130Cas was not changed in Myr-FAK transfectants. Finally, we confirmed that the transfection of the CAS-FL plasmid was highly efficient, by detecting high levels of the c-Myc-tag, since this is a myc-tagged plasmid.

\section{Discussion}

Induction of anoikis as a novel mechanism of antitumor effect

Breakdown of anoikis is a critical step in tumor progression and metastatic spread because it enables malignant cells to detach
FIGURE 5 - Immunolocalization of p130Cas in TD20 and HCA7 cells after $15 \mathrm{hr}$ of treatment with vehicle or $60 \mu \mathrm{M}$ celecoxib. (a) In TD20 and HCA7 control cells, p130Cas was localized in the cytosol and plasma membrane (red). When cells were treated with celecoxib, p130Cas was translocated to the nucleus, while some staining was remaining in the cytosol. (b) Nuclear staining with colorant Hoescht (green). (c) Combination of p130Cas immunofluorescence (red) and nuclear staining with Hoescht (green) to asses the nuclear localization of p130Cas (yellow). In control cells nuclei remained green colored, thus p130Cas was absent. When cells were treated with celecoxib, nuclear localization of p130Cas was clearly observed (yellow). Images were obtained by fluorescence microscopy $(\times 630)$.

\section{$\underline{\text { TD20 }}$}

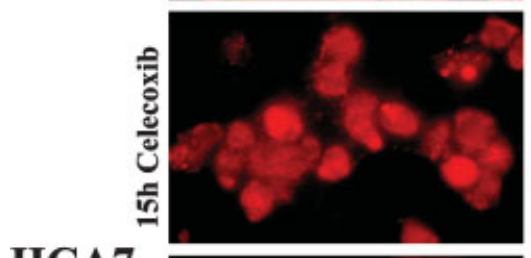

$\underline{\mathrm{HCA} 7}$
A. p130CAS
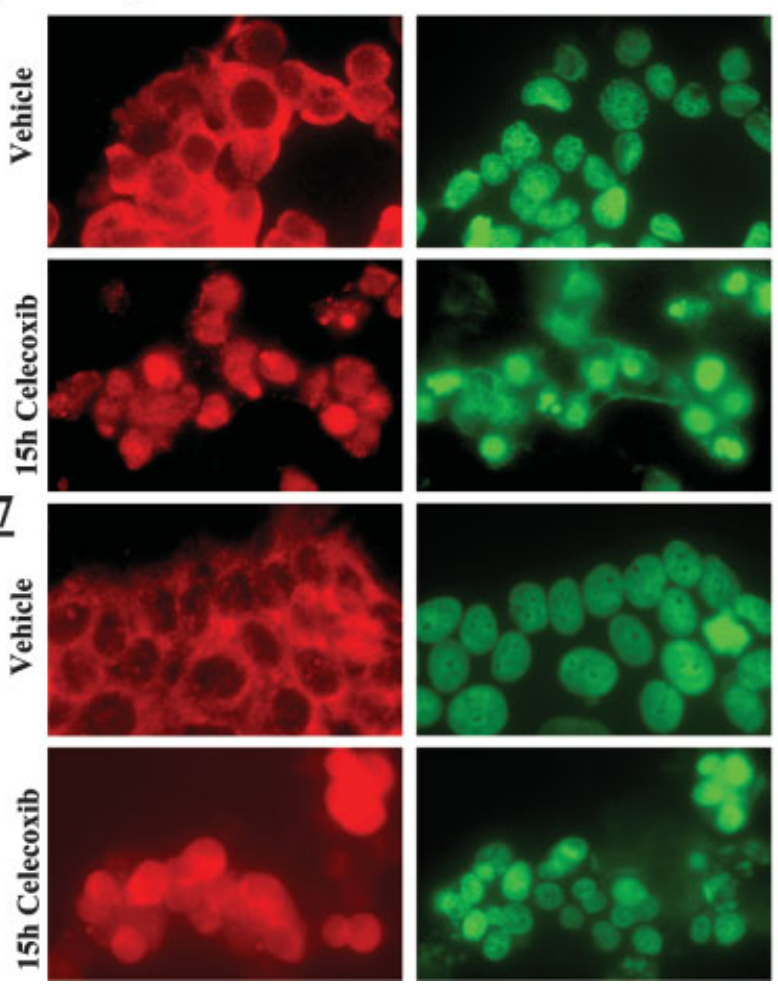

B. Hoescht

C. p130CAS+Hoescht
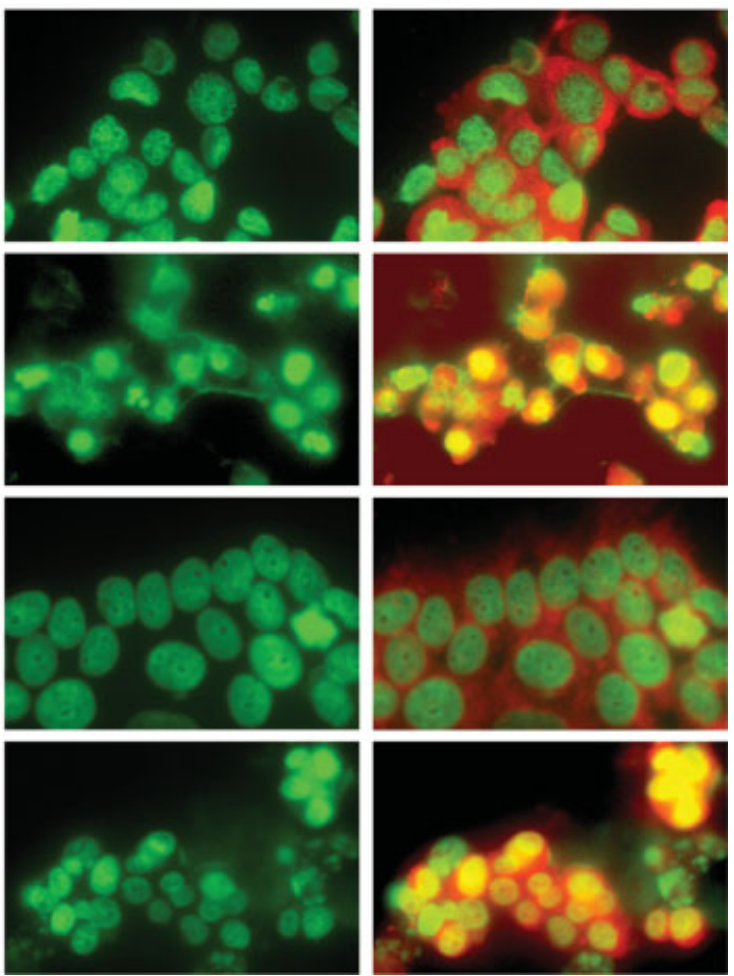
A.

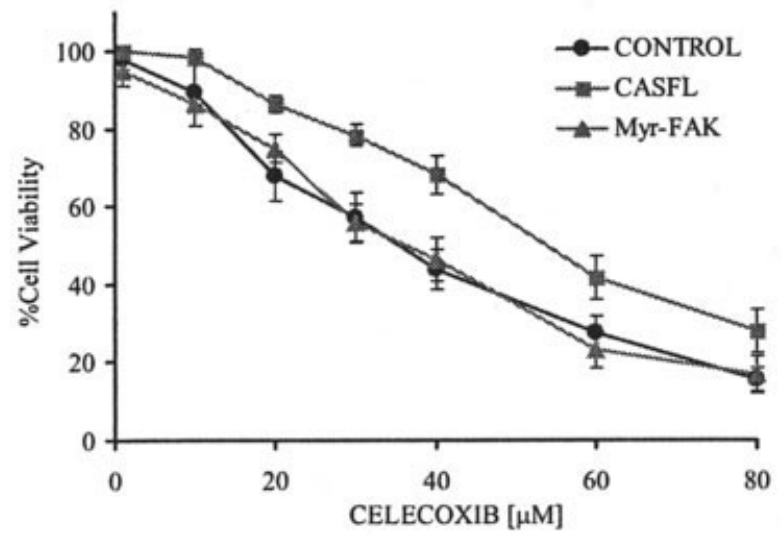

B.
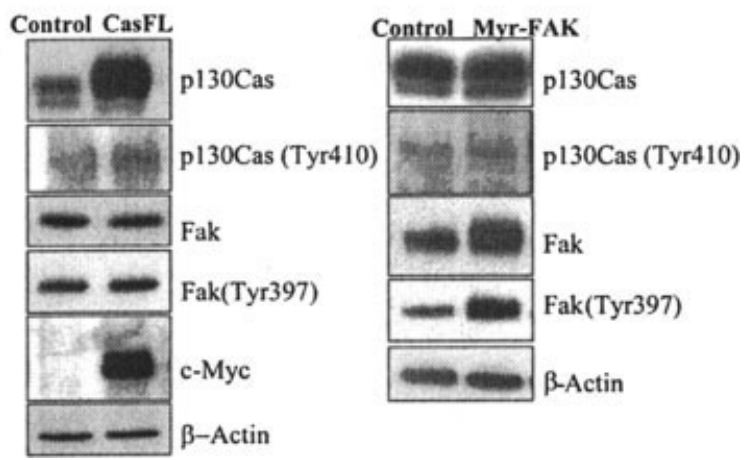

Figure 6 - Effect of p130Cas overexpression or FAK activation on the cytotoxic effect of celecoxib. (a) Viability/concentration curves for celecoxib in the transfected cells (control, CAS-FL and Myr-FAK) after $4 \mathrm{hr}$ of exposure to the drug. The overexpression of wild-type p130Cas partially reverts the cytotoxic effect of celecoxib in TD20 cells, whereas the expression of activated FAK does not. The $\mathrm{IC}_{50}$ of celecoxib in cells transfected with CAS-FL was significantly higher than that in cells transfected with pcDNA3 (control) (U-Mann Whitney test, $p=0.026$ ). (b) The molecular analysis of the transfectants showed that CAS-FL transfected cells depicted higher levels of expression and activation of p130Cas (as assessed by Tyr410 phosphorylation) than did control transfectants. Overexpression of p130Cas did not alter the level of expression or activation (Tyr397) of FAK. The efficacy of the transfection was also validated by immunoblotting against c-myc, since CAS-FL is a myc-tagged plasmid. Myr-FAK transfectants showed an increase in activation and expression of FAK, without altering the levels of p130Cas. Equal loading was checked by immunoblotting against $\beta$-actin.

from the primary tumor and invade secondary tissues. ${ }^{21,46}$ Therefore, new therapies directed to sensitize tumor cells to anoikis are especially relevant, since they could have both antitumor and antimetastatic properties. Here, we describe anoikis as a mechanism of action for celecoxib, based on the observation of its induction of apoptosis and deregulation of focal adhesion proteins.

\section{A relevant role for p130Cas in anoikis induction by celecoxib}

Our results show that the loss of cell anchorage and anoikis induced by celecoxib is associated with the proteolysis of p130Cas. Despite previous reports of FAK involvement in regulating the sensitivity to anoikis, our results suggest that, in our system, FAK does not play a relevant role in this effect. This is because it shows an inconsistent pattern of dephosphorylartion and the overexpression of constitutive active FAK does not alter the sensitivity of the cells to the drug. However, it has been reported that overexpression of constitutively active FAK suppresses anoikis in a variety of cells, ${ }^{47}$ whereas FAK gene silencing promotes anoikis and suppresses the metastatic process in human pancreatic adenocarcinomas. ${ }^{48}$ Moreover, there is evidence suggesting that some antitumor drugs can modulate signaling through focal adhesion proteins. ${ }^{49,50}$ Thus, deregulation of FAK expression and induction of anoikis has been proposed as a mechanism of antitumor action for quinazoline derivatives in prostate cancer cells. ${ }^{51,52}$ Nevertheless, none of these drugs are chemically related to celecoxib. Therefore, we believe that a FAK-dependent anoikis pathway exists that differs from the p130Cas-dependent anoikis we have observed in our system, in which FAK does not appear to be involved. Similarly, in our system, and based on the absence of dephosphorylation of AKT in the tested cell lines, we think that AKT does not play a significant role in the effect of celecoxib. This is consistent with a previous report describing that the cleaved p130Cas fragment induces AKT-independent anoikis in lung carcinoma cells. ${ }^{45}$ In contrast, other authors have observed an AKT-dependent effect for celecoxib in the HT29 cell line. ${ }^{9}$ The differences in AKT-dependency between their and our results are most likely due to the lower dosage of celecoxib used in our assays.

Our results point out to a central role for p130Cas in the antitumor effect of celecoxib, in colon carcinoma cells. Thus, in all tested cell lines, we have observed that celecoxib induces the proteolysis of p130Cas, generating a $31 \mathrm{kDa}$ fragment, which may contribute to the induction of anoikis in two ways. On the one hand, we have observed that this fragment is partially localized in the plasma membrane and cytosol where it can act as a dominant negative, blocking the interaction of p130Cas with its interacting proteins. ${ }^{45}$ On the other hand, the $31 \mathrm{kDa}$ fragment is translocated to nucleus where it may induce the execution of anoikis. ${ }^{45}$ Thus, the $\mathrm{p} 130 \mathrm{Cas}$ cleavage product can repress the heterodimerization of E2A transcription factors altering the expression of some genes such as p21 WAF135. We still did not test this transcriptional repression effect, nevertheless, our results suggest a prominent role of p130Cas in the apoptotic effect of celecoxib.

Therefore, our findings of an early p130Cas proteolysis in all studied cell lines and the significant changes in sensitivity to celecoxib of the p130Cas overexpressing cells support the notion that, in our system, disruption of focal adhesion complexes plays a relevant role in the induction of cell killing by celecoxib. This effect happens mainly because of p130Cas deregulation, which appears to be more relevant that the possible, but inconsistent, deregulation of FAK.

The fact that overexpression of wild-type p130Cas only partially reverts the cytotoxic effect of celecoxib could be due to the coexistence of anoikis with other forms of apoptosis, which may also activate the mitochondrial pathway. This partial reversion may also be due to the fact that wild-type p130Cas only interferes with one of the two different activities of the $31 \mathrm{kDa}$ proteolytic fragment. Thus, overexpression of p130Cas can minimize the $31 \mathrm{kDa}$ fragment inhibitory effect on the antiapoptotic transduction signals generated in the focal adhesions, but cannot block the nuclear translocation of the cleaved protein and its action as inductor of apoptosis. Our results are consistent with previous reports, suggesting a relevant role for p130Cas in the regulation of the sensitivity to apoptosis and anoikis. Thus, overexpression of wild-type p130Cas protects cells from the apoptosis induced by the leukocyte common antigen-related tyrosine phosphatase $^{53}$ whereas dominant-negative forms of p130Cas inhibit cell survival mediated by FAK. ${ }^{32}$ Furthermore, in lung adenocarcinoma cells, anchorage-independent phosphorylation of p130Cas protects from anoikis. ${ }^{54}$ In addition, cleavage of p130Cas has been reported during anoikis in epithelial cells ${ }^{45}$ as well as in apoptotic induction by etoposide, ${ }^{33,34}$ nocodazole or staurosporine. ${ }^{55}$ Moreover, modulation of integrin-mediated signaling by sulindac sulfide, associated with dephosphorylation of FAK, p130Cas and rearrangement of the actin cytoskeleton, has also been reported in colon carcinoma cells. ${ }^{17}$ 
Celecoxib induces anoikis before or concurrently with other forms of mitochondrial apoptosis

The timing of p130Cas deregulation also supports anoikis induction, through focal adhesion disassembling, as a relevant part of celecoxib antitumor effect, in our system. Thus, we have used p130Cas proteolysis as a marker of anoikis induction because it is an early event, functionally involved in the initiation of this process. ${ }^{45}$ In all the analyzed cell lines, we have observed that p130Cas proteolysis always occurs at the same time as, or before, caspase-9 activation. Moreover, in at least the TD20 cell line, the proteolysis of p130Cas occurs before the activation of caspase-9. This is consistent with previous reports of p130Cas proteolysis before caspase activation, and the only partial block of p130Cas cleavage by the pan-caspase inhibitor ZVAD in MDCK cells, suggesting the involvement of other proteases, particularly at early stages of p130Cas cleavage. ${ }^{44}$

Nevertheless, in our system, celecoxib also induces mitochondrial apoptosis, since we observed release of cytochrome $\mathrm{C}$ from the mitochondria and activation of caspase 9. These results replicate previous reports of procaspase- 9 activation and cytochrome $\mathrm{C}$ release by celecoxib in cholangiocarcinoma or lymphoma cells. $^{16,43,44}$

Therefore, in our system, anoikis appears to coexist with other forms of mitochondrial apoptosis. This conclusion is based on these 3 additional findings: (i) Higher increase in cytochrome C release than in p130Cas proteolysis, observed in HCA7 cells (which could be due to the additive or synergistic effect of the concurrent induction of anoikis and other forms of mitochondrial apoptosis), (ii) p130Cas overexpression produces only a partial reversion of the sensitivity to the drug, and (iii) Floating viable cells coexist with nonviable cells early after celecoxib exposure. Thus, the loss of anchorage observed after celecoxib treatment may had been both the cause and the consequence of apoptosis.

\section{COX-2 independence of the celecoxib mechanism of action and its clinical relevance}

Our results appear to support a COX-2 independent antitumor effect for celecoxib. First of all, cells that do not express COX-2 remain sensitive to the drug, and there is no correlation between the level of COX-2 expression and the sensitivity of cells to the cytotoxic or the apoptotic effect of celecoxib. In addition, the concentration of celecoxib that inhibits cell viability in our colon cancer cells is higher than the concentration needed to inhibit COX-2 activity. This observation is in agreement with other authors who also support a COX-2 independent antitumor effect for celecoxib both in vitro ${ }^{56}$ and in vivo. ${ }^{4}$ In addition, it is important to remark that the concentration of celecoxib used in our studies is clinically relevant and achievable. Plasma concentrations of celecoxib have been reported up to $8 \mu \mathrm{M}$ in humans. ${ }^{57}$ Although these concentra- tions are significantly lower than those used in vitro, they do not reflect the levels of drug achieved in the intestinal tract (where colorectal tumors arise) where concentrations of celecoxib are 320 times higher than in plasma. ${ }^{58}$

Moreover, the last reports on the cardiovascular toxicity associated with the clinical use of COX-2 inhibitors, enhances the interest on the analysis of the COX-2 independent mechanisms of action of celecoxib. In fact, this toxicity has prompted the withdrawal of rofecoxib and valdecoxib from the market. ${ }^{59,60}$ Moreover, FDA is requesting manufacturers of all other prescription NSAIDs (including celecoxib) to include boxed warnings highlighting the potential for increased risk of cardiovascular events and gastrointestinal bleeding associated with their use. The cardiovascular toxicity of these compounds appears to depend on its COX-2 inhibitory activity, which blocks prostacyclin synthesis. ${ }^{61}$ Thus, the identification of COX-2 independent therapeutic targets for antitumor activity of celecoxib opens the possibility to perform structure-activity analysis in order to develop new compounds that maintain their antitumor activity without inhibiting COX-2. Thus, other authors have chemically dissociated the antitumor and COX-2 inhibitory activities, synthesizing derivatives with the same basic structure as celecoxib. ${ }^{62-65}$

In conclusion, we have demonstrated that celecoxib induces anoikis by deregulating focal adhesion signaling. This deregulation includes, in all tested colon carcinoma cells, the cleavage of p130Cas to generate a $31 \mathrm{kDa}$ fragment, which is translocated to the nucleus, leading to the activation of the mitochondrial apoptotic pathway. Thus, we believe that disruption of focal adhesion complexes, through p130Cas deregulation, plays a relevant role in the induction of cell killing by this drug. In contrast, FAK and AKT do not appear to be involved in this effect. Nevertheless, in our system anoikis coexists with other forms of mitochondrial apoptosis. This is the first time that induction of anoikis is identified as part of the mechanism of action of celecoxib. Furthermore, our results suggest that inhibition of signaling from focal adhesion proteins is a promising target for antitumor drug development. This antitumor mechanism of action could be effective in inhibiting both, the growth of the primary tumors as well as in the metastatic process, since anchorage-independent survival in the bloodstream and attachment in the target tissues is associated with increased focal adhesion signaling. ${ }^{66}$

\section{Acknowledgements}

We would like to acknowledge Luis Carlos Navas and Monica Gomez for their technical support. We also want to thank Dr. Amy Bouton and Dr. Silvio Gutkind for generously providing the CAS-FL and Myr-FAK plasmids, respectively, and Dr. Susan Kirkland for her kind gift of the HCA7 cell line.

\section{References}

1. Rigau J, Pique JM, Rubio E, Planas R, Tarrech JM, Bordas JM. Effects of long-term sulindac therapy on colonic polyposis. Ann Intern Med 1991;115:952-4.

2. DuBois RN, Giardiello FM, Smalley WE. Nonsteroidal anti-inflammatory drugs, eicosanoids, and colorectal cancer prevention. Gastroenterol Clin North Am 1996;25:773-91.

3. Reddy BS, Rao CV, Seibert K. Evaluation of cyclooxygenase-2 inhibitor for potential chemopreventive properties in colon carcinogenesis. Cancer Res 1996;56:4566-9.

4. Steinbach G, Lynch PM, Phillips RK, Wallace MH, Hawk E, Gordon GB, Wakabayashi N, Saunders B, Shen Y, Fujimura T, Su LK, Levin B. The effect of celecoxib, a cyclooxygenase-2 inhibitor, in familial adenomatous polyposis. N Engl J Med 2000;342: 1946-52.

5. Kawamori T, Rao CV, Seibert K, Reddy BS. Chemopreventive activity of celecoxib, a specific cyclooxygenase-2 inhibitor, against colon carcinogenesis. Cancer Res 1998;58:409-12.

6. Sheng H, Shao J, Kirkland SC, Isakson P, Coffey RJ, Morrow J, Beauchamp RD, DuBois RN. Inhibition of human colon cancer cell growth by selective inhibition of cyclooxygenase-2. J Clin Invest 1997; 99:2254-9.
7. Goldman AP, Williams CS, Sheng H, Lamps LW, Williams VP, Pairet M, Morrow JD, DuBois RN. Meloxicam inhibits the growth of colorectal cancer cells. Carcinogenesis 1998;19:2195-9.

8. Sanborn R, Blanke CD. Cyclooxygenase-2 inhibition in colorectal cancer: boom or bust? Semin Oncol 2005;32:69-75.

9. Arico S, Pattingre S, Bauvy C, Gane P, Barbat A, Codogno P, OgierDenis E. Celecoxib induces apoptosis by inhibiting 3-phosphoinositide-dependent protein kinase-1 activity in the human colon cancer HT-29 cell line. J Biol Chem 2002;277:27613-21.

10. Yamazaki R, Kusunoki N, Matsuzaki T, Hashimoto S, Kawai S. Selective cyclooxygenase- 2 inhibitors show a differential ability to inhibit proliferation and induce apoptosis of colon adenocarcinoma cells. FEBS Lett 2002;531:278-84.

11. Johnson AJ, Hsu AL, Lin HP, Song X, Chen CS. The cyclo-oxygenase-2 inhibitor celecoxib perturbs intracellular calcium by inhibiting endoplasmic reticulum $\mathrm{Ca}^{2+}$-ATPases: a plausible link with its anti-tumour effect and cardiovascular risks. Biochem J 2002;366: $831-7$.

12. Zhang Z, Lai GH, Sirica AE. Celecoxib-induced apoptosis in rat cholangiocarcinoma cells mediated by Akt inactivation and Bax translocation. Hepatology 2004;39:1028-37. 
13. Leng J, Han C, Demetris AJ, Michalopoulos GK, Wu T. Cyclooxygenase-2 promotes hepatocellular carcinoma cell growth through Akt activation: evidence for Akt inhibition in celecoxib-induced apoptosis. Hepatology 2003;38:756-68.

14. Hsu AL, Ching TT, Wang DS, Song X, Rangnekar VM, Chen CS. The cyclooxygenase-2 inhibitor celecoxib induces apoptosis by blocking Akt activation in human prostate cancer cells independently of Bcl-2. J Biol Chem 2000;275:11397-403.

15. Kim SH, Song SH, Kim SG, Chun KS, Lim SY, Na HK, Kim JW Surh YJ, Bang YJ, Song YS. Celecoxib induces apoptosis in cervical cancer cells independent of cyclooxygenase using NF- $\mathrm{\kappa B}$ as a possible target. J Cancer Res Clin Oncol 2004;130:551-60.

16. Jendrossek V, Handrick R, Belka C. Celecoxib activates a novel mitochondrial apoptosis signaling pathway. FASEB J 2003;17:1547-9.

17. Weyant MJ, Carothers AM, Bertagnolli ME, Bertagnolli MM. Colon cancer chemopreventive drugs modulate integrin-mediated signaling pathways. Clin Cancer Res 2000;6:949-56.

18. Obara S, Nakata M, Takeshima H, Katagiri H, Asano T, Oka Y, Maruyama I, Kuratsu J. Integrin-linked kinase (ILK) regulation of the cell viability in PTEN mutant glioblastoma and in vitro inhibition by the specific COX-2 inhibitor NS-398. Cancer Lett 2004;208:115-22.

19. Frisch SM, Screaton RA. Anoikis mechanisms. Curr Opin Cell Biol 2001:13:555-62.

20. Frisch SM, Francis H. Disruption of epithelial cell-matrix interactions induces apoptosis. J Cell Biol 1994;124:619-26.

21. Shanmugathasan M, Jothy S. Apoptosis, anoikis and their relevance to the pathobiology of colon cancer. Pathol Int 2000;50:273-9.

22. Hanks SK, Polte TR. Signaling through focal adhesion kinase. Bioessays 1997:19:137-45.

23. Rankin S, Rozengurt E. Platelet-derived growth factor modulation of focal adhesion kinase (p125FAK) and paxillin tyrosine phosphorylation in Swiss 3T3 cells. Bell-shaped dose response and cross-talk with bombesin. J Biol Chem 1994;269:704-10.

24. Schaller MD, Hildebrand JD, Shannon JD, Fox JW, Vines RR, Parsons JT. Autophosphorylation of the focal adhesion kinase pp125FAK, directs SH2-dependent binding of pp60src. Mol Cell Biol 1994;14:1680-8.

25. Chen HC, Appeddu PA, Isoda H, Guan JL. Phosphorylation of tyrosine 397 in focal adhesion kinase is required for binding phosphatidylinositol 3-kinase. J Biol Chem 1996;271:26329-34.

26. Schlaepfer DD, Hanks SK, Hunter T, van der Geer P. Integrin-mediated signal transduction linked to Ras pathway by GRB2 binding to focal adhesion kinase. Nature 1994;372:786-91.

27. Tamura M, Gu J, Danen EH, Takino T, Miyamoto S, Yamada KM PTEN interactions with focal adhesion kinase and suppression of the extracellular matrix-dependent phosphatidylinositol 3-kinase/Akt cell survival pathway. J Biol Chem 1999;274:20693-703.

28. Polte TR, Hanks SK. Interaction between focal adhesion kinase and Crk-associated tyrosine kinase substrate p130Cas. Proc Natl Acad Sci USA 1995;92:10678-82.

29. Klemke RL, Leng J, Molander R, Brooks PC, Vuori K, Cheresh DA. CAS/Crk coupling serves as a "molecular switch" for induction of cell migration. J Cell Biol 1998;140:961-72.

30. Nojima Y, Mimura T, Morino N, Hamasaki K, Furuya H, Sakai R Nakamoto T, Yazaki Y, Hirai $H$. Tyrosine phosphorylation of p130Cas in cell adhesion and transformation. Hum Cell 1996;9:16974

31. Cho SY, Klemke RL. Extracellular-regulated kinase activation and CAS/Crk coupling regulate cell migration and suppress apoptosis during invasion of the extracellular matrix. J Cell Biol 2000;149:223-36.

32. Chan PC, Lai JF, Cheng CH, Tang MJ, Chiu CC, Chen HC. Suppression of ultraviolet irradiation-induced apoptosis by overexpression of focal adhesion kinase in Madin-Darby canine kidney cells. J Biol Chem 1999;274:26901-6.

33. Kook S, Shim SR, Choi SJ, Ahnn J, Kim JI, Eom SH, Jung YK, Paik SG, Song WK. Caspase-mediated cleavage of p130cas in etoposideinduced apoptotic Rat-1 cells. Mol Biol Cell 2000;11:929-39.

34. Shim SR, Kook S, Kim JI, Song WK. Degradation of focal adhesion proteins paxillin and p130cas by caspases or calpains in apoptotic rat-1 and L929 cells. Biochem Biophys Res Commun 2001;286:601-8.

35. Kim W, Kook S, Kim DJ, Teodorof C, Song WK. The 31-kDa caspase-generated cleavage product of p130cas functions as a transcriptional repressor of E2A in apoptotic cells. J Biol Chem 2004;279: $8333-42$.

36. Tarafa G, Villanueva A, Farre L, Rodriguez J, Musulen E, Reyes G, Seminago R, Olmedo E, Paules AB, Peinado MA, Bachs O, Capella G. DCC and SMAD4 alterations in human colorectal and pancreatic tumor dissemination. Oncogene 2000;19:546-55.

37. Guerrero S, Casanova I, Farre L, Mazo A, Capella G, Mangues R. $\mathrm{K}$-ras codon 12 mutation induces higher level of resistance to apoptosis and predisposition to anchorage-independent growth than codon 13 mutation or proto-oncogene overexpression. Cancer Res 2000;60: $6750-6$.
38. Burnham MR, Harte MT, Bouton AH. The role of SRC-CAS interactions in cellular transformation: ectopic expression of the carboxy terminus of CAS inhibits SRC-CAS interaction but has no effect on cellular transformation. Mol Carcinog 1999;26:20-31.

39. Igishi T, Fukuhara S, Patel V, Katz BZ, Yamada KM, Gutkind JS Divergent signaling pathways link focal adhesion kinase to mitogenactivated protein kinase cascades. Evidence for a role of paxillin in c-Jun NH(2)-terminal kinase activation. J Biol Chem 1999;274:3073846.

40. Zweifel BS, Davis TW, Ornberg RL, Masferrer JL. Direct evidence for a role of cyclooxygenase 2-derived prostaglandin E2 in human head and neck xenograft tumors. Cancer Res 2002;62:6706-11.

41. Leahy KM, Ornberg RL, Wang Y, Zweifel BS, Koki AT, Masferrer JL. Cyclooxygenase-2 inhibition by celecoxib reduces proliferation and induces apoptosis in angiogenic endothelial cells in vivo. Cancer Res 2002:62:625-31.

42. Li P, Nijhawan D, Budihardjo I, Srinivasula SM, Ahmad M, Alnemri ES, Wang X. Cytochrome c and dATP-dependent formation of Apaf-1/ caspase-9 complex initiates an apoptotic protease cascade. Cell 1997; 91:479-89.

43. Lai GH, Zhang Z, Sirica AE. Celecoxib acts in a cyclooxygenase-2independent manner and in synergy with emodin to suppress rat cholangiocarcinoma growth in vitro through a mechanism involving enhanced Akt inactivation and increased activation of caspases-9 and -3. Mol Cancer Ther 2003;2:265-71.

44. Wu T, Leng J, Han C, Demetris AJ. The cyclooxygenase-2 inhibitor celecoxib blocks phosphorylation of Akt and induces apoptosis in human cholangiocarcinoma cells. Mol Cancer Ther 2004;3:299-307.

45. Wei L, Yang Y, Zhang X, Yu Q. Cleavage of p130Cas in anoikis. J Cell Biochem 2004;91:325-35.

46. Yawata A, Adachi M, Okuda H, Naishiro Y, Takamura T, Hareyama M, Takayama S, Reed JC, Imai K. Prolonged cell survival enhances peritoneal dissemination of gastric cancer cells. Oncogene 1998; 16:2681-6.

47. Frisch SM, Vuori K, Ruoslahti E, Chan-Hui PY. Control of adhesiondependent cell survival by focal adhesion kinase. J Cell Biol 1996; 134:793-9.

48. Duxbury MS, Ito H, Zinner MJ, Ashley SW, Whang EE. Focal adhesion kinase gene silencing promotes anoikis and suppresses metastasis of human pancreatic adenocarcinoma cells. Surgery 2004;135:55562

49. Obara S, Nakata M, Takeshima H, Kuratsu J, Maruyama I, Kitajima I Inhibition of migration of human glioblastoma cells by cerivastatin in association with focal adhesion kinase (FAK). Cancer Lett 2002; 185:153-61

50. Permpongkosol S, Wang JD, Takahara S, Matsumiya K, Nonomura N, Nishimura K, Tsujimura A, Kongkanand A, Okuyama A. Anticarcinogenic effect of FTY720 in human prostate carcinoma DU145 cells: modulation of mitogenic signaling, FAK, cell-cycle entry and apoptosis. Int J Cancer 2002;98:167-72.

51. Keledjian K, Kyprianou N. Anoikis induction by quinazoline based $\alpha 1$-adrenoceptor antagonists in prostate cancer cells: antagonistic effect of bcl-2. J Urol 2003;169:1150-6.

52. Walden PD, Globina Y, Nieder A. Induction of anoikis by doxazosin in prostate cancer cells is associated with activation of caspase-3 and a reduction of focal adhesion kinase. Urol Res 2004;32:261-5.

53. Weng LP, Wang $\mathrm{X}, \mathrm{Yu} \mathrm{Q}$. Transmembrane tyrosine phosphatase LAR induces apoptosis by dephosphorylating and destabilizing p130Cas. Genes Cells 1999:4:185-96.

54. Wei L, Yang Y, Zhang X, Yu Q. Anchorage-independent phosphorylation of p130(Cas) protects lung adenocarcinoma cells from anoikis. J Cell Biochem 2002;87:439-49.

55. Kook S, Shim SR, Kim JI, Ahnn JH, Jung YK, Paik SG, Song WK. Degradation of focal adhesion proteins during nocodazole-induced apoptosis in rat-1 cells. Cell Biochem Funct 2000;18:1-7.

56. Bae SH, Jung ES, Park YM, Kim BS, Kim BK, Kim DG, Ryu WS. Expression of cyclooxygenase-2 (COX-2) in hepatocellular carcinoma and growth inhibition of hepatoma cell lines by a COX-2 inhibitor, NS-398. Clin Cancer Res 2001:7:1410-18.

57. Davies NM, McLachlan AJ, Day RO, Williams KM. Clinical pharmacokinetics and pharmacodynamics of celecoxib: a selective cyclooxygenase-2 inhibitor. Clin Pharmacokinet 2000;38:225-42.

58. Paulson SK, Zhang JY, Breau AP, Hribar JD, Liu NW, Jessen SM, Lawal YM, Cogburn JN, Gresk CJ, Markos CS, Maziasz TJ, Schoenhard GL, et al. Pharmacokinetics, tissue distribution, metabolism, and excretion of celecoxib in rats. Drug Metab Dispos 2000;28:51421

59. Psaty BM, Furberg CD. COX-2 inhibitors-lessons in drug safety. N Engl J Med 2005:352:1133-5

60. Drazen JM. COX-2 inhibitors-a lesson in unexpected problems. N Engl J Med 2005;352:1131-2

61. McAdam BF, Catella-Lawson F, Mardini IA, Kapoor S, Lawson JA, FitzGerald GA. Systemic biosynthesis of prostacyclin by cyclooxyge- 
nase (COX)-2: the human pharmacology of a selective inhibitor of COX-2. Proc Natl Acad Sci USA 1999;96:272-7.

62. Song X, Lin HP, Johnson AJ, Tseng PH, Yang YT, Kulp SK, Chen CS. Cyclooxygenase-2, player or spectator in cyclooxygenase-2 inhibitor-induced apoptosis in prostate cancer cells. J Natl Cancer Inst 2002;94:585-91.

63. Zhu J, Song X, Lin HP, Young DC, Yan S, Marquez VE, Chen CS Using cyclooxygenase-2 inhibitors as molecular platforms to develop a new class of apoptosis-inducing agents. J Natl Cancer Inst 2002; 94:1745-57.
64. Kusunoki N, Ito T, Sakurai N, Suguro T, Handa H, Kawai S. A novel celecoxib derivative potently induces apoptosis of human synovial fibroblasts. J Pharmacol Exp Ther 2005:314:796-803.

65. Ding H, Han C, Zhu J, Chen CS, D’Ambrosio SM. Celecoxib derivatives induce apoptosis via the disruption of mitochondrial membrane potential and activation of caspase 9. Int J Cancer 2005;113: 803-10.

66. Korb T, Schluter K, Enns A, Spiegel HU, Senninger N, Nicolson GL, Haier J. Integrity of actin fibers and microtubules influences metastatic tumor cell adhesion. Exp Cell Res 2004;299:236-47. 